\title{
Mass Spectrometric Quantification of the Antimicrobial Peptide Pep19-2.5 with Stable Isotope Labeling and Acidic Hydrolysis
}

\author{
Sabrina Wohlfart ${ }^{1,+}{ }^{+}$, Michael Kilian ${ }^{1,+}$, Philip Storck ${ }^{1}$, Thomas Gutsmann ${ }^{2}$, Klaus Brandenburg ${ }^{3}$ and \\ Walter Mier 1 ,* \\ 1 Department of Nuclear Medicine, Heidelberg University Hospital, 69120 Heidelberg, Germany; \\ sabrina.wohlfart@med.uni-heidelberg.de (S.W.); m.kilian@dkfz-heidelberg.de (M.K.); \\ philip.storck@med.uni-heidelberg.de (P.S.) \\ 2 Division of Biophysics Research Center Borstel, Leibniz-Center for Medicine and Bioscience, 23845 Borstel, \\ Germany; tgutsmann@fz-borstel.de \\ 3 Brandenburg Antiinfektiva GmbH, Parkallee 10b, 23845 Borstel, Germany; kbrandenburg@fz-borstel.de \\ * Correspondence: walter.mier@med.uni-heidelberg.de; Tel.: +49-62-2156-7720 \\ + These authors contributed equally to this work.
}

check for updates

Citation: Wohlfart, S.; Kilian, M.; Storck, P.; Gutsmann, T.;

Brandenburg, K.; Mier, W. Mass Spectrometric Quantification of the Antimicrobial Peptide Pep19-2.5 with Stable Isotope Labeling and Acidic Hydrolysis. Pharmaceutics 2021, 13, 1342. https://doi.org/10.3390/ pharmaceutics13091342

Academic Editor: Sangkyu Lee

Received: 20 July 2021

Accepted: 23 August 2021

Published: 27 August 2021

Publisher's Note: MDPI stays neutral with regard to jurisdictional claims in published maps and institutional affiliations.

Copyright: (c) 2021 by the authors. Licensee MDPI, Basel, Switzerland. This article is an open access article distributed under the terms and conditions of the Creative Commons Attribution (CC BY) license (https:// creativecommons.org/licenses/by/ $4.0 /)$.

\begin{abstract}
Sepsis is the number one cause of death in intensive care units. This life-threatening condition is caused by bacterial infections and triggered by endotoxins of Gram-negative bacteria that leads to an overreaction of the immune system. The synthetic anti-lipopolysaccharide peptide Pep19-2.5 is a promising candidate for the treatment of sepsis as it binds sepsis-inducing lipopolysaccharides and thus prevents initiation of septic shock. For clinical evaluation precise quantification of the peptide in blood and tissue is required. As the peptide is not extractable from biological samples by commonly used methods there is a need for a new analysis method that does not rely on extraction of the peptide. In order to quantify the peptide by mass spectrometry, the peptide was synthesized containing ${ }^{13} \mathrm{C}_{9}{ }_{1}^{15} \mathrm{~N}_{1}$-labeled phenylalanine residues. This modification offers high stability during acidic hydrolysis. Following acidic hydrolysis of the samples, the concentration of ${ }^{13} \mathrm{C}_{9},{ }^{15} \mathrm{~N}_{1}$-labeled phenylalanine determined by LC-MS could be unambiguously correlated to the content of Pep19-2.5. Further experiments validated the accuracy of the data. Moreover, the quantification of Pep19-2.5 in different tissues (as studied in Wistar rats) was shown to provide comparable results to the results obtained with radioactively-labeled $\left({ }^{14} \mathrm{C}\right)$ Pep19-2.5- Radioactive labeling is considered as the gold standard for quantification of compounds that refrain from reliable extraction methods. This novel method represents a valuable procedure for the determination of Pep19-2.5 and sticky peptides with unpredictable extraction properties in general.
\end{abstract}

Keywords: sepsis; antimicrobial peptides; SALP; peptide labeling; stable isotope labeling; mass spectrometry

\section{Introduction}

Bacterial infections cause approximately 8-9 million of deaths each year worldwide. In most cases, bacterial infections can be treated by the use of antibiotics. Unfortunately, the increasing prevalence of resistant germs (the best-known being MRSA), augments the number of systemic infections eventually resulting in sepsis [1,2]. The burden of sepsis is the number one cause of death in intensive care units and estimated to affect $15 \%$ of deaths worldwide [3]. On the contrary, the number of new antibiotics approved by the authorities (e.g., FDA, BfArM) is continuously decreasing [4,5]. On that score, a gap in supplies of antibiotics will arise in the future [6]. Closing this gap with drugs providing the required pathogen-specificity can be achieved with drugs that specifically reduce the toxicological effects of bacteria.

Antimicrobial peptides (AMP) constitute a promising therapeutic option [7]. In contrast to standard antibiotics that interact directly with bacteria by growth inhibition the 
reproduction or cytotoxicity, AMP bind lipopolysaccharides (LPS), compounds specifically occurring in the outer membrane of Gram-negative bacteria. LPS are essential compounds of the bacterial cell wall and nontoxic. When released from the cell wall into the human blood system, LPS constitute a major sepsis induction factor. LPS bind to CD14, a surface protein mainly located on macrophages and monocytes. CD14 forms a complex with individual receptors such as TLR4, MD-2, and other surface proteins. The CD14-bound TLR4 triggers intracellular signal pathways, which activate immune cells. These cells release pro-inflammatory cytokines which activate the innate immune system provoking an inflammatory response (Figure 1) [8].

\section{Antibiotics SALP}
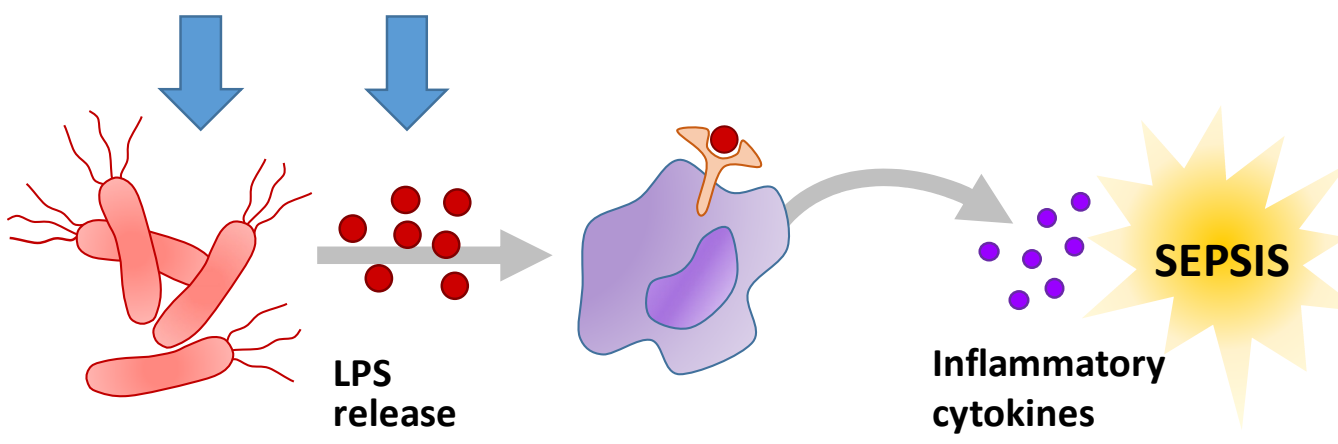

Figure 1. General mechanism of sepsis initiation caused bacterial infections and the target points of antibiotics and the LPS neutralizing icosapeptide Pep19-2.5.

Lysis of bacteria leads to increased release of LPS followed by an increased activation of the immune system. This eventually leads to sepsis, a detrimental host response to infection. Over-activation of the immune system can lead to coagulation disorders and organ dysfunction. Currently, cardiorespiratory resuscitation and early intravenous antibiotic therapy represent current standard therapy of sepsis [9].

In order to neutralize LPS, Brandenburg et al. developed anti-LPS-peptides (synthetic anti-lipopolysaccharide peptide $=$ SALP) [10]. The peptides are characterized by their high specific binding to LPS and a low toxicity under physiological conditions and are thought to prevent sepsis (Figure 1). Sequences of the SALPs were originally based on the Limulus anti-LPS factor, but the subsequent rational design resulted in the selection of the novel patent-protected Pep19-2.5 (also known as Aspidasept), being the most promising candidate out of a large number of sequence variations. It shows high binding affinity for free LPS, high endotoxin neutralization capacity in vitro and antiseptic and anti-inflammatory effects in mouse models. In contrast to alternative approaches, the peptide shows an excellently balanced anti-endotoxic versus antibacterial ratio. Furthermore, experiments show the peptide to inhibit cytokine production in human immune cells [11]. In addition, Pep19-2.5 binds and neutralizes bacterial pathogenic factors from Gram-positive bacteria [12]. It shows that the peptide is able to neutralize free and membrane- bound toxins [13]. The highly specific binding to LPS is probably achieved by the amphiphilic character of Pep19-2.5. The predominantly positive charged moiety of the peptide, interacting with the negative charged moiety of LPS, is supplemented by hydrophobic C-terminus of the peptide resulting in a surface that matches the complementary structural elements of LPS [14].

The peptide is not extractable from biological samples, so another method for analysis is necessary. One standard procedure is the organic solvent extraction of serum and following LC-MS analysis of the supernatant. For this, different solvents like methanol, acetone, chloroform or acetonitrile are most commonly used. In all cases the $\mathrm{pH}$-value is important for the extraction efficiency [15]. To increase the efficiency, it might be possible to add a chelating agent like EDTA or use non-ionic hydrophilic polymers. Another possibility is the solid phase extraction of the peptide/drug with a polymeric sorbent and a following 
drying process prior to analysis [16]. For the analysis of organ distribution, a useful tool is MALDI-TOF analysis of organ sections [17]. An additional way for quantification without extraction and for organ distribution, is the use of a radioactive labeled compound and the measurement of radioactivity in the different samples [18]. With this method an indirect quantification of the amount of peptide is correlated.

As of now there was no analytical method for blood and tissue samples of the antimicrobial peptide Pep19-2.5 except for methods that involve radioactive labeling. Here, we report a novel method for the quantification of Pep19-2.5 by implementing marker amino acids. The marker amino acids are labeled with stable isotopes. Here, ${ }^{13} \mathrm{C}_{9},{ }^{15} \mathrm{~N}_{1}$-labeled phenylalanine was used, which had no effect on the antimicrobial activity. The quantification of the peptide in biological samples (e.g., serum) is achieved by acidic serum hydrolysis without requiring extensive handling. The amount of ${ }^{13} \mathrm{C}_{9},{ }^{15} \mathrm{~N}_{1}$-labeled phenylalanine quantified by LC-MS can be unambiguously correlated to the dosed amount of Pep19-2.5. The great advantage is that this method can be used for serum and for analysis of all other biological samples (e.g., organ distributions). An overview of this method is given in Figure 2.
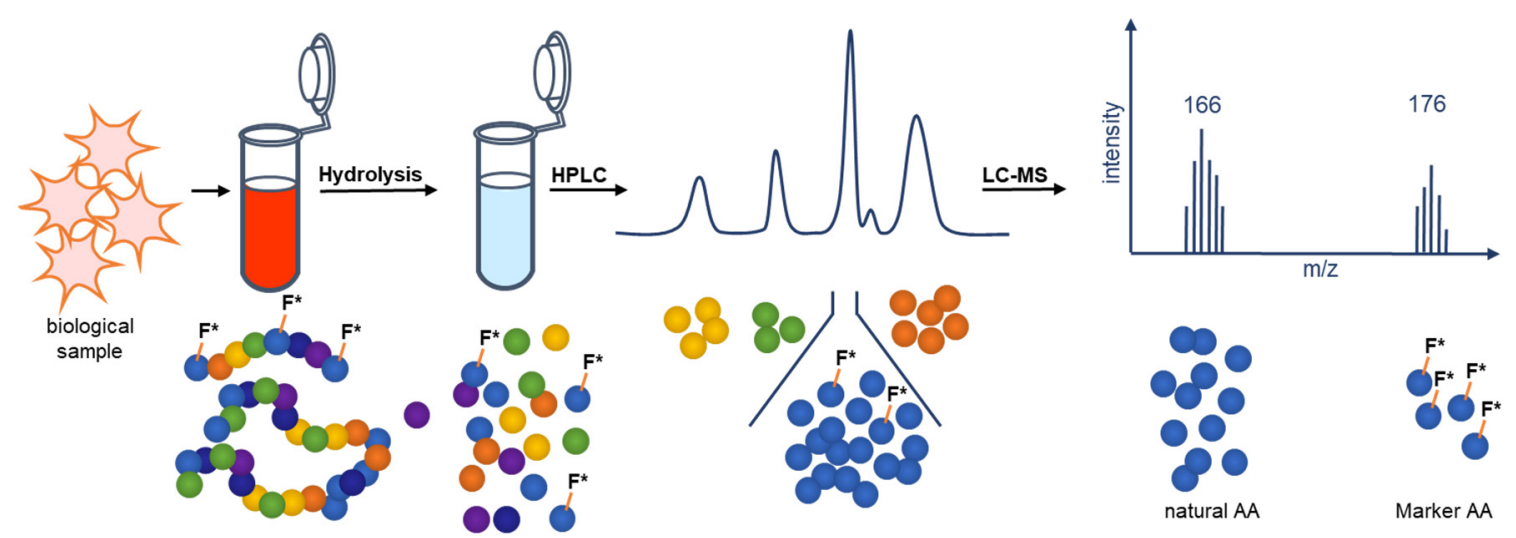

Figure 2. Schematic presentation of the principle of the novel mass spectrometric quantification method of Pep19-2.5 in biological samples. The quantification of Pep19-2.5 is possible after acidic hydrolysis and LC-MS analysis by implementing marker amino acids $\left({ }^{13} \mathrm{C}_{9},{ }^{15} \mathrm{~N}_{1}\right.$ phenylalanine).

\section{Materials and Methods}

\subsection{Peptide Synthesis}

${ }^{13} \mathrm{C}_{9},{ }^{15} \mathrm{~N}_{1}$-labeled phenylalanine (Sigma-Aldrich GmbH, Taufkirchen, Germany) was Fmoc-protected using standard procedures [19]. Subsequently, the peptide synthesis of the Pep19-2.5 derivative containing four ${ }^{13} \mathrm{C}_{9},{ }^{15} \mathrm{~N}_{1}$-labeled phenylalanine residues (analyte, Figure 3) was carried out by standard manual Fmoc/tBu solid-phase peptide synthesis on Fmoc-Rink amide resin (TentaGel R RAM, Rapp Polymere GmbH, Tübingen, Germany) [20]. The Fmoc-protected L-amino acids were purchased from ORPEGEN Peptide Chemicals $\mathrm{GmbH}$ (Heidelberg, Germany). For coupling of the isotope-labeled amino acid, 2 equivalents and a coupling time of $2.5 \mathrm{~h}$ was used.

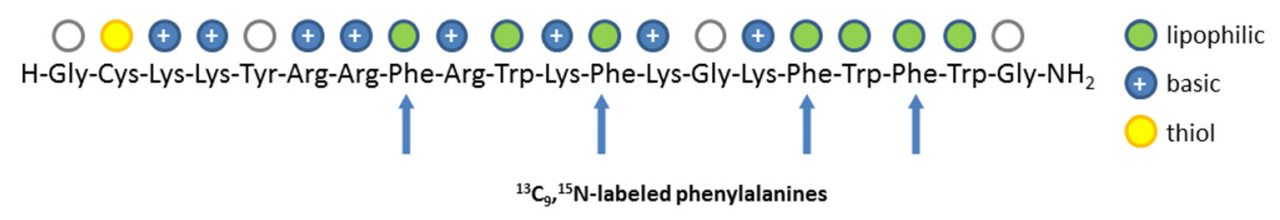

Figure 3. Sequence of Pep19-2.5. The arrows indicate the positions of the ${ }^{13} \mathrm{C}_{9},{ }^{15} \mathrm{~N}_{1}$-labeled phenylalanine residues incorporated in the solid phase peptide synthesis.

The synthesis of deuterated Pep19-2.5 was carried out on an automated synthesizer (433A, Applied Biosystems, Waltham, MA, USA) on Fmoc-Rink amide resin. For the 
synthesis of the Pep19-25 derivative containing 32 deuterium atoms, eightfold deuterated Fmoc-protected phenylalanine (Sigma Aldrich, GmbH, Taufkirchen, Germany) was used and applied in excess of two equivalents. Pep19-2.5 labeled with ${ }^{14} \mathrm{C}$ was obtained from Rainer Bartels (Leibniz-Zentrum für Medizin und Biowissenschaften, Borstel, Germany).

\subsection{Acidic Hydrolysis}

For acidic hydrolysis $10 \mu \mathrm{L}^{13} \mathrm{C}_{6}$ (ring) phenylalanine ( $1 \mathrm{mg} / \mathrm{mL}$ stock) were added as internal standard to $200 \mu \mathrm{L}$ water containing ${ }^{13} \mathrm{C}_{9},{ }^{15} \mathrm{~N}_{1}$ phenylalanine (for calibration curve) or human serum (from voluntary donors) containing Pep19-2.5 with four ${ }^{13} \mathrm{C}_{9},{ }^{15} \mathrm{~N}_{1}$ phenylalanine residues. After addition of $270 \mu \mathrm{L}$ hydrochloric acid (10 M), the samples were hydrolyzed at $120^{\circ} \mathrm{C}$ for $24 \mathrm{~h}$. Subsequently, the solvent was evaporated in a vacuum evaporator (HETOVAC) at $40^{\circ} \mathrm{C}$ for $4 \mathrm{~h}$ and the pellet was resuspended in water to achieve the applied concentration.

\subsection{HPLC Analysis}

HPLC analysis was performed using an Agilent 1100 system with an UV-detection at $214 \mathrm{~nm}$. As stationary phase a Chromolith ${ }^{\circledR}$ Performance RP-18e 100-3 mm column (Merck KGaA, Darmstadt, Germany) was used. A 5 min linear gradient from 100\% water (+0.05\% trifluoroacetic acid (TFA)) to 100\% acetonitrile (+0.05\% TFA) was applied.

\subsection{LC-MS Analysis}

LC-MS analysis was performed using an ESI-Orbitrap mass spectrometer (Exactive,

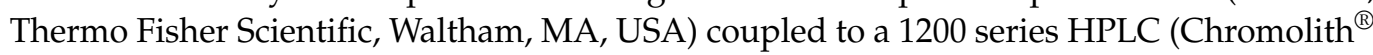
Performance RP-18e 100-4.6 mm, Agilent Technologies, Santa Clara, CA, USA). A 20 min linear gradient from $100 \%$ water $(+0.05 \%$ TFA) to $100 \%$ acetonitrile $(+0.05 \%$ TFA) was used. The mass range was between 100 and $400 \mathrm{~m} / z$. For MS peak integration, the software implemented in the mass analyzer was used (Qual Browser, Thermo Scientific, Waltham, MA, USA).

\subsection{LC-MS/MS Analysis}

The LC-MS/MS system (Thermo Fisher Scientific, Waltham, MA, USA) consisted of a P4000 LC pump, and a triple-stage quadrupole mass spectrometer (Thermo TSQ 7000) equipped with electrospray ionization (API-2 ion source) at $4.5 \mathrm{kV}$. For chromatographic separation, a Phenomenex Synergy Hydro RP column $(4 \mu \mathrm{m}, 2.1 \times 150 \mathrm{~mm})$ with an integrated pre-column was used at $50{ }^{\circ} \mathrm{C}$. The eluent consisted of ammonium acetate (5 mM including $0.1 \%$ aqueous formic acid, $2.5 \%$ acetonitrile, and $2.5 \%$ methanol) (A) and acetonitrile/methanol (50/50) (B). The flow rate was $0.5 \mathrm{~mL} / \mathrm{min}$ and was introduced without splitting into the ESI source. The gradient started at $100 \% \mathrm{~A}$. Within 3 min, the ratio was changed linear to $60 \% \mathrm{~A} / 40 \% \mathrm{~B}$ and subsequently within 0.5 min changed linear to $6 \% \mathrm{~A} / 94 \% \mathrm{~B}$ and kept stable until $6 \mathrm{~min}$. Within the next $0.5 \mathrm{~min}$, the system returned to starting conditions, and another $2.5 \mathrm{~min}$ were given for equilibration. The injection volume was $50 \mu \mathrm{L}$. The TSQ 7000 was tuned automatically to phenylalanine and the internal standards using the Xcalibur 1.4 system software and standard optimization procedures. Multiple reaction monitoring (MRM) analysis was performed using argon as collision gas at $2.0 \mathrm{mTorr}$ for collision-induced dissociation (CID), and the MS/MS transitions monitored in the positive ion mode were $m / z 166.1 \rightarrow m / z 120.1$ for Phe, $m / z 171.1 \rightarrow m / z 125.1$ for Phe-d5, and $m / z 174.1 \rightarrow m / z 128.1$ each at $18 \mathrm{~V}$.

\subsection{Biodisdribution of ${ }^{14}$ C-Labeled Pep19-2.5}

Isotope labeled compounds represent the current gold standard for organ distribution studies. Animal treatment was carried out at the Department of Nuclear Medicine, University Hospital Heidelberg, in accordance with institutional guidelines and the German animal welfare act. NMRI mice (Janvier Labs, Le Genest-Saint-Isle, France) were anesthetized with isoflurane. $100 \mu \mathrm{L}$ of the radioactive peptide (corresponding to approximately 
$70,000 \mathrm{cpm}$ ) supplemented with cold peptide at a concentration of $1 \mathrm{mg} / \mathrm{mL}$ (in $0.9 \% \mathrm{NaCl}$ ) were injected intravenously into the tail vain of the NMRI mice and the organs were dissected at the defined times after sacrificing the mice with $\mathrm{CO}_{2}$. The following organs were dissected: blood, heart, lung, liver, spleen, kidney, muscle, intestine, stomach, brain, femur, tail (injection site). Due to the uncommon properties of Pep19-2.5 (a substantial amount of the peptide sticks to the tail), the whole tail was taken in different sections for solubilization. Organ weights were approximated using published data and data provided by the animal supplier (Janvier Labs, Le Genest-Saint-Isle, France) [21].

Tissue samples were placed in scintillation tubes and incubated for approximately $20 \mathrm{~h}$ at $50-60{ }^{\circ} \mathrm{C}$ with $1 \mathrm{~mL}$ of solubilizer $\left(5 \% N, N^{\prime}\right.$ dimethyldodecylamine- $N$-oxide solution (Sigma-Aldrich GmbH, Taufkirchen, Germany), 5\% Tergitol type 15-S-7 (Sigma-Aldrich $\mathrm{GmbH}$, Taufkirchen, Germany), 2.5\% NaOH). For blood, liver, spleen, heart, lung and kidney samples, $0.1 \mathrm{~mL}$ of $0.1 \mathrm{M}$ EDTA was added in order to avoid foam formation. For discoloration, $0.1-0.4 \mathrm{~mL}$ of $\mathrm{H}_{2} \mathrm{O}_{2}(30 \%)$ was carefully added and samples were incubated for $1 \mathrm{~h}$ at $50-60{ }^{\circ} \mathrm{C}$. After bleaching, $10 \mathrm{~mL}$ of the scintillation liquid Ultima Gold (PerkinElmer Inc., Waltham, MA, USA) was added. Samples were measured in a betacounter (1414 Wallac Liquid Scintillation Counter, PerkinElmer, Waltham, MA, USA) at room temperature.

\subsection{Biodistribution ${ }^{2}$ H-Labeled Pep19-2.5}

Animals were treated as described above. The in vivo experiments were approved by the Animal Welfare Board of the Governmental Office (Regierungspräsidium, Karlsruhe, Germany; permit G-127/18) and the University of Heidelberg Committee for Ethics on Laboratory Animal Experimentation and were performed in compliance with institutional guidelines, the German law for animal protection, the Directive 2010/63/EU and FELASA (Federation of European Laboratory Animal Science Associations, Ipswich, UK) guidelines. In total, $200 \mu \mathrm{L}$ of a sterile filtered $5 \mathrm{mg} / \mathrm{mL}$ solution of the deuterated peptide Pep19-2.5 was injected into Wistar rats (Janvier Labs, Le Genest-Saint-Isle, France). The animals were sacrificed and organ samples were dissected and weighed. Depending on the experimental setup, a defined amount of the internal standard Phe-d5 (CDN Isotopes Inc., Pointe-Claire, QC, Canada) was added to the samples. For organ samples, $1 \mu \mathrm{g}$ Phe-d5 per mg sample was added.

The samples were hydrolyzed with $6 \mathrm{~N} \mathrm{HCl}$ for $24 \mathrm{~h}$ at $110{ }^{\circ} \mathrm{C}$. Then, the samples were filtered with glass wool followed by sterile filtration (Millex-GV $0.22 \mu \mathrm{m}$, Merck). $\mathrm{HCl}$ was evaporated in samples of $40 \mu \mathrm{L}$ in vacuo at room temperature for $2 \mathrm{~h}$. Neutralization was achieved by addition of saturated sodium bicarbonate solution after dissolution of the samples in water. Serum samples were measured using LC-MS and organ distribution samples were measured using LC-MS/MS.

All animal trials were approved by the Animal Care and Use committees at the Regierungspräsidium Karlsruhe, Germany.

\section{Results}

In this article, a novel mass spectrometric method for the analysis of Pep19-2.5 in biological samples is described. Below, each step of the analysis method is described in detail for the ${ }^{13} \mathrm{C}_{9},{ }^{15} \mathrm{~N}_{1}$ labeled compound. For the development of this method and the proof of principle in the first experiments, deuterated phenylalanine was used.

\subsection{Selection of Amino Acid}

For an accurate determination it is necessary to select an amino acid which is stable under the extreme conditions in the hydrolysis step $\left(24 \mathrm{~h}, 120^{\circ} \mathrm{C}\right)$. Moreover, the development of the method is facilitated if the amino acid is UV-active and more importantly in case of hydrophobic amino acids that are separated from the bulk of amino acids by RP-HPLC. Due to this, the three aromatic amino acids phenylalanine, tryptophan and tyrosine were hydrolyzed, and their stability analyzed by HPLC, as shown in Figure 4. 

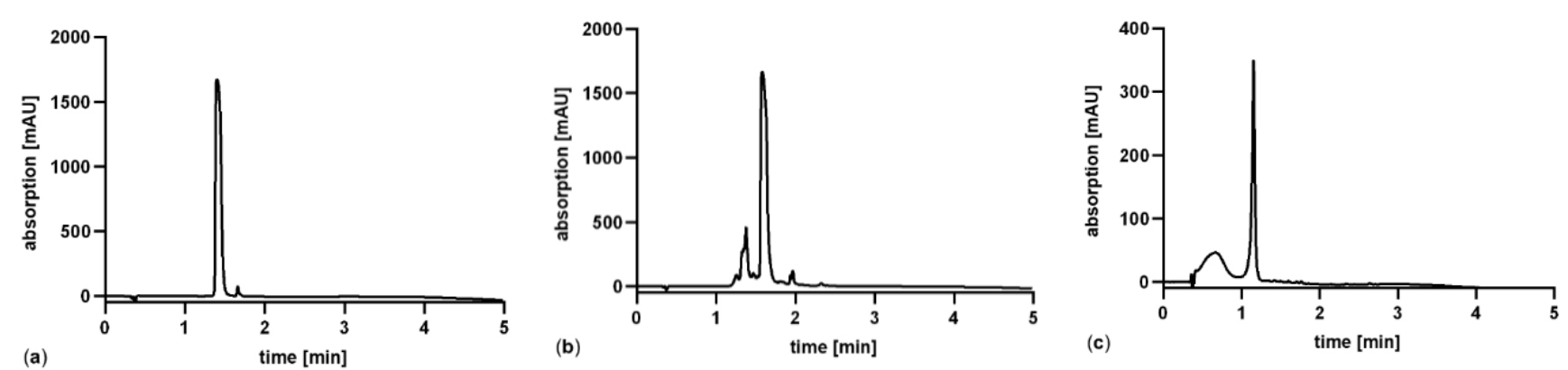

Figure 4. HPLC-analysis after acidic hydrolysis of aromatic amino acids (a) phenylalanine, (b) tryptophan and (c) tyrosine for $24 \mathrm{~h}$ at $120^{\circ} \mathrm{C}$. The original concentration of each amino acid prior hydrolysis was $1 \mathrm{mg} / \mathrm{mL}$.

As seen in Figure 4 it is obvious, that only phenylalanine (Figure 4a) is sufficiently stable during the hydrolysis process. Tryptophan forms several degradation products and tyrosine is degraded to poorly soluble products as reflected by the reduction of its UV-absorption peak. Another positive aspect is that the peptide Pep19-2.5 contains four phenylalanine residues, resulting in a fourfold higher sensitivity for this amino acid after hydrolysis.

\subsection{Normalization of ${ }^{13} \mathrm{C}_{9},{ }^{15} \mathrm{~N}_{1}$ Phenylalanine to Internal Standard}

First attempts using deuterated phenylalanine derivative revealed high deuterium hydrogen exchange ratios under the hydrolysis conditions. For the consistency of the measurements, it was therefore necessary to use ${ }^{13} \mathrm{C}_{6}$ (ring)-labeled phenylalanine as internal standard in every sample in a defined amount of $0.05 \mathrm{mg} / \mathrm{mL}$. With this knowledge and Equation (1), it is possible to normalize all measured ${ }^{13} \mathrm{C}_{9},{ }^{15} \mathrm{~N}_{1}$ phenylalanine values and compare them.

$$
\mathrm{AUC}_{\text {Phe, normalized }}=\frac{\left|\mathrm{IS}_{\text {Blank }}-\mathrm{IS}_{\text {Sample }}\right|}{\mathrm{IS}_{\text {Blank }}} \cdot \mathrm{AUC}_{\text {Phe, Sample }}
$$

\subsection{Establishment of a Calibration Curve}

In the subsequent step, a ${ }^{13} \mathrm{C}_{9},{ }^{15} \mathrm{~N}_{1}$ phenylalanine standard curve, as shown in Figure 5, was determined for concentrations between 0.74 and $190.48 \mu \mathrm{M}$. The values detected were in excellent accordance with the linear plot. At lower concentrations, a reliable detection of ${ }^{13} \mathrm{C}_{9},{ }^{15} \mathrm{~N}_{1}$ phenylalanine was not possible.

The linear regression resulted in:

$$
\text { concentration Phe }[\mu \mathrm{M}]=\frac{\text { abundance }+2301}{60,499}
$$

With a coefficient of determination for the linear fit of 0.9999 . The calculation of the amount of Pep19-2.5 in biological samples is now possible:

$$
\text { concentration Pep19-2.5 }[\mu \mathrm{M}]=\frac{1}{4} \text { concentration Phe }[\mu \mathrm{M}]
$$




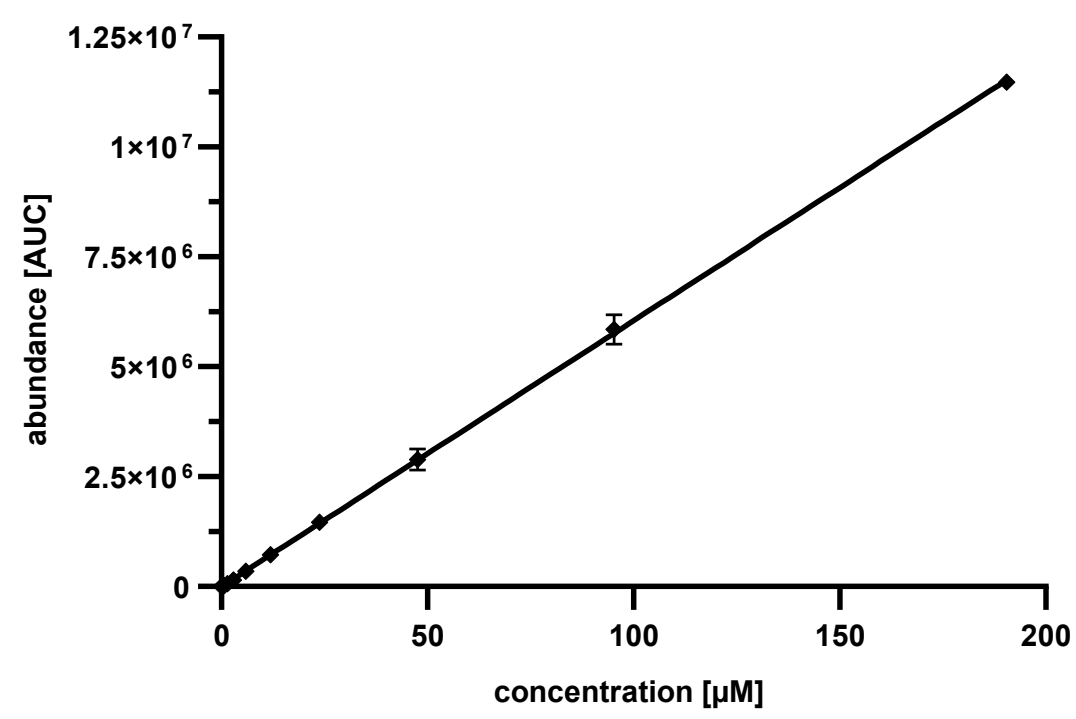

Figure $5 .{ }^{13} \mathrm{C}_{9},{ }^{15} \mathrm{~N}_{1}$ phenylalanine standard curve after acidic hydrolysis. The error was calculated by standard deviation, the number of experiments was $n=3$, the coefficient of determination for the linear fit was 0.9999 .

\subsection{Validation of Data}

To determine the accuracy of the established method, known amounts of Pep19-2.5 $\left(4 \times{ }^{13} \mathrm{C}_{9},{ }^{15} \mathrm{~N}_{1}\right.$ phenylalanine) were dissolved in human serum, hydrolyzed, evaporated and dissolved in water. Subsequently, the content of ${ }^{13} \mathrm{C}_{9},{ }^{15} \mathrm{~N}_{1}$ phenylalanine was determined by LC-MS analysis and the quantity of Pep19-2.5 was calculated using the generated standard curve. For a clear comparison between the adjusted concentration and the determined concentration via phenylalanine standard curve, the values were plotted as shown in Figure 6.

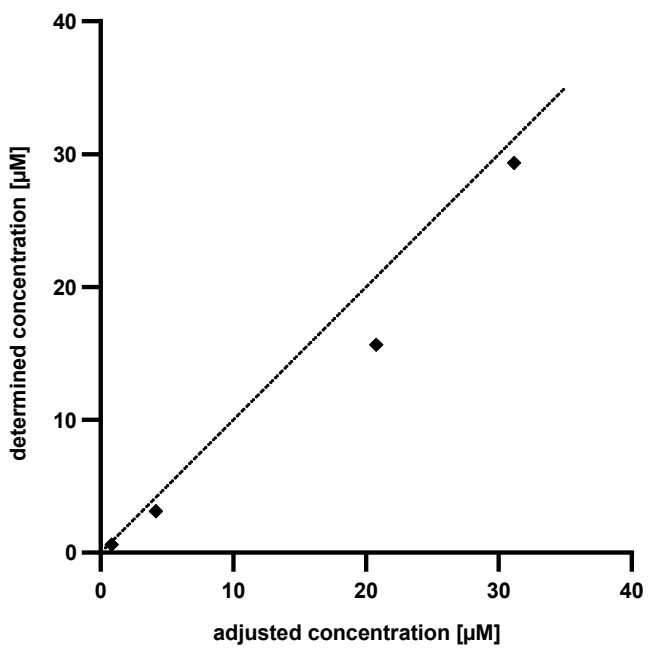

Figure 6. Plot of the determined concentration of Pep19-2.5 $\left(4 \times{ }^{13} \mathrm{C}_{9},{ }^{15} \mathrm{~N}_{1}\right.$ phenylalanines $)$ against the adjusted concentration of Pep19-2.5 $\left(4 \times{ }^{13} \mathrm{C}_{9},{ }^{15} \mathrm{~N}_{1}\right.$ phenylalanines). The dotted line shows the calculated concentration of Pep19-2.5 $\left({ }^{13} \mathrm{C}_{9},{ }^{15} \mathrm{~N}_{1}\right.$ phenylalanine).

As Figure 6 implies, the determined concentration of Pep19-2.5 $\left(4 \times{ }^{13} \mathrm{C}_{9},{ }^{15} \mathrm{~N}_{1}\right.$ phenylalanine) is lower than the adjusted one. This was attributed to an incomplete recovery from the serum. The discrepancies between the calculated and the adjusted concentrations accounted to approximately $25 \%$ in each measurement. Based on this knowledge it is possible to introduce a correction factor and to precisely determine the amounts of Pep19-2.5 $\left(4 \times{ }^{13} \mathrm{C}_{9},{ }^{15} \mathrm{~N}_{1}\right.$ phenylalanine $)$ in human serum. 


\subsection{Biodistribution}

The results for organ distribution of ${ }^{14} \mathrm{C}$-labeled Pep19-2.5 are shown in Figure 7. The peptide initially accumulates in the lungs resulting in high $\% \mathrm{ID} / \mathrm{g}$ values. The activity in the lungs decreased significantly after $15 \mathrm{~min}$, whereas this case was not as strong in the other organs. Significant amounts of the peptide were located in spleen, liver, kidney and tail. $\% \mathrm{ID} / \mathrm{g}$ values for the spleen and intestine doubled over $4 \mathrm{~h}$. Sixty minutes post injection, the activity was almost completely cleared from the blood. When considering the whole organs, the majority of the peptide was found in the liver over the entire measurement period (46 to $69 \% \mathrm{ID}$ ). A small portion was also found in the kidneys (Figure 8a,c).

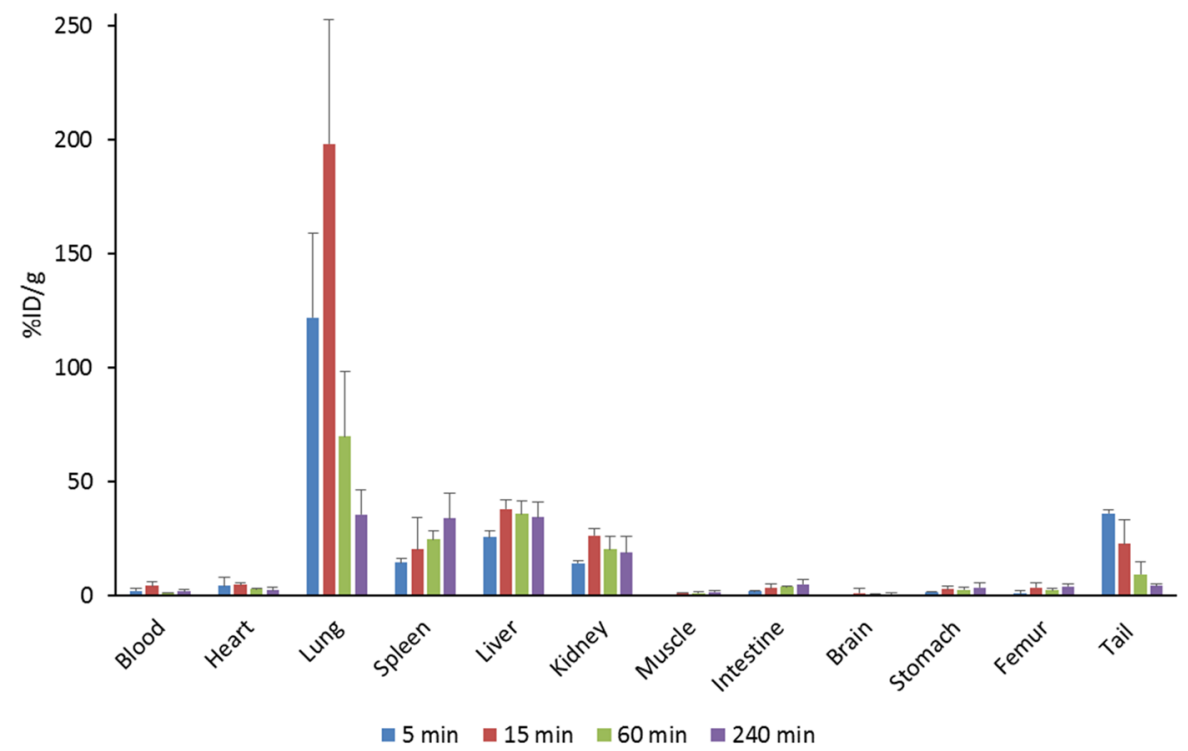

Figure 7. Biodistribution of ${ }^{14} \mathrm{C}$-labeled Pep19-2.5 in NMRI mice.
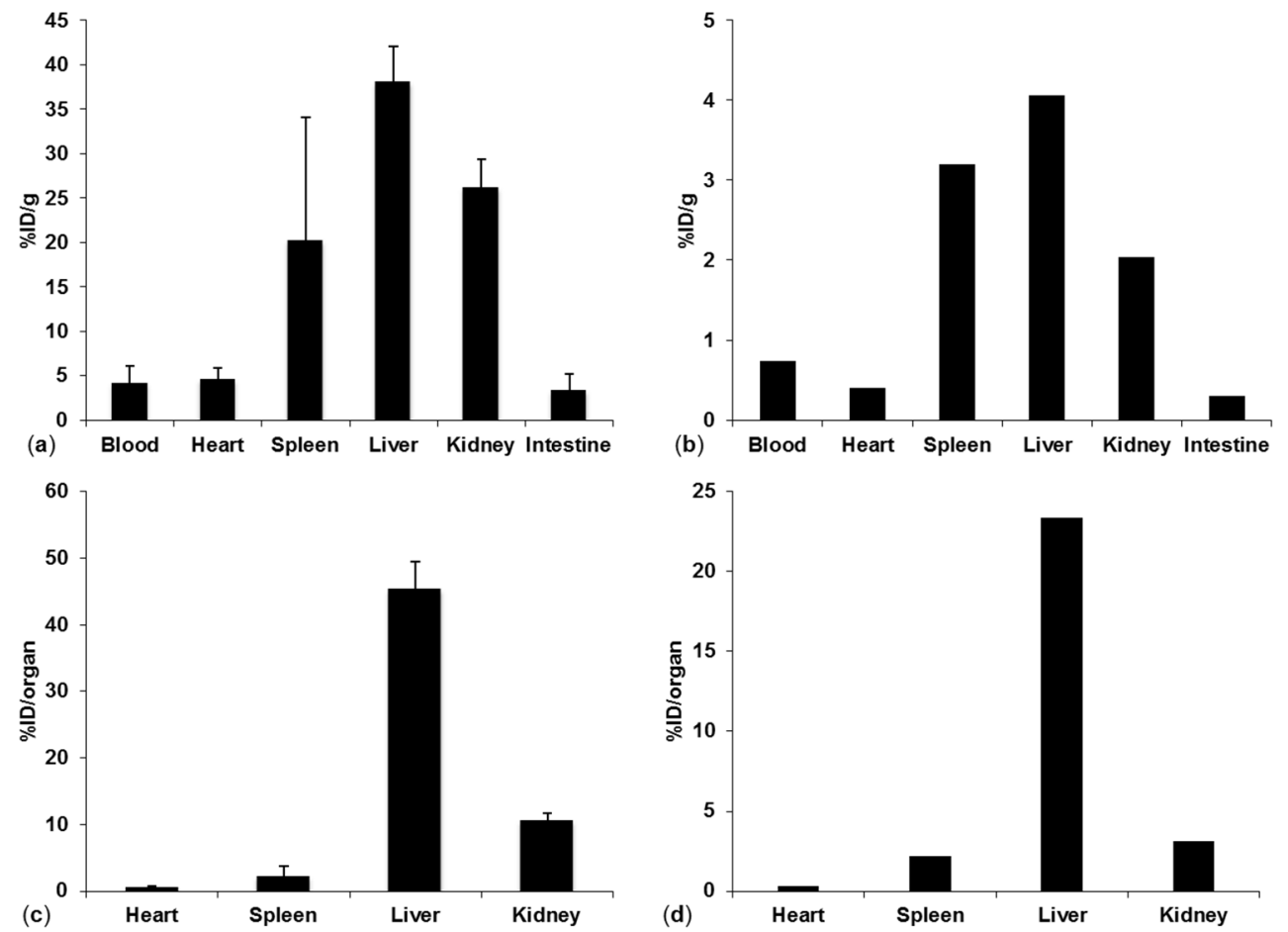

Figure 8. (a) \%ID/g for ${ }^{14} \mathrm{C}$-labeled Pep19-2.5 organ distribution in NMRI mice, (b) \%ID/g ${ }^{2} \mathrm{H}-$ labeled Pep19-2.5 in a Wistar rat, (c) \%ID/organ for ${ }^{14} \mathrm{C}$-labeled Pep19-2.5 in mice, (d) \%ID/organ for ${ }^{2} \mathrm{H}$-labeled Pep19-2.5 in a Wistar rat 15 min post injection. 
Organ distribution for the deuterated Pep19-2.5 was performed in a Wistar rat $15 \mathrm{~min}$ post injection. The results are shown in Figure 8. Since the injected peptide solution containing the ${ }^{2} \mathrm{H}$-labeled peptide was filtered with a sterile filter, aggregation was reduced in this approach which resulted in lower accumulation and \% ID/g values in the lungs. However, comparing the other organs, the approach based on quantification of the deuterated peptide resulted in similar relative \%ID/g values (Figure $8 a, b$ ). When quantifying the peptide in whole organs, the majority of the peptide was found to be in the liver as consistently determined by both approaches (Figure 8c,d).

\section{Discussion}

The prevention of sepsis by Pep19-2.5 is a promising new approach, because the peptide efficiently neutralizes bacterial toxins such as LPS and could be used against whole body infections. Today, LC-MS is the standard procedure for the analysis of peptides and small proteins. In the standard analysis protocols, the analyte is separated from the matrix (e.g., the serum) and quantified using LC-MS or LC-MS/MS. In cases in which the analyte cannot be unambiguously quantified, for example because of concentrations below the detection limit or problems in matrix separation, indirect quantification by a radiolabeled derivative can be used. Most common in that case is the use of tritium and carbon-14 labeled peptides.

Until now, there was no possibility to detect the peptide Pep19-2.5 directly in animal studies or patient's serum other than methods based on radioactively labeled derivatives. For this purpose, a novel method based on stable isotope labeling, acidic hydrolysis and LC-MS analysis to quantify the peptide in biological samples was developed. With the recorded phenylalanine standard curve, it is now feasible to calculate the amount of Pep19-2.5 in human serum and other biological samples via precise determination of ${ }^{13} \mathrm{C}_{9},{ }^{15} \mathrm{~N}_{1}$ phenylalanine.

It was shown that this method can be used to determine the concentrations of Pep19-2.5 in rat organs and human serum. Until now, there was no possibility to detect the peptide Pep19-2.5 in animal studies or patient's serum other than methods based on radioactively labeled derivatives. Furthermore, it is possible to transfer this analysis method to other peptides, which are not extractable from biological samples.

Author Contributions: Conceptualization, S.W., K.B., T.G. and W.M.; methodology, S.W. and W.M.; software, S.W.; validation, S.W. and P.S., formal analysis, S.W. and M.K.; investigation, S.W. and M.K. resources, W.M.; data curation S.W. and P.S.; writing-original draft preparation, S.W. and M.K.; writing-review and editing, S.W., P.S. and W.M.; visualization, S.W.; supervision, W.M.; project administration, T.G. and W.M. All authors have read and agreed to the published version of the manuscript.

Funding: This research was funded by Zentrales Innovationsprogramm Mittelstand (ZIM), grant number ZF4380802NK7.

Institutional Review Board Statement: The in vivo experiments were approved by the Animal Welfare Board of the Governmental Office (Regierungspräsidium, Karlsruhe, Germany; permit G-127/18) and the University of Heidelberg Committee for Ethics on Laboratory Animal Experimentation and were performed in compliance with institutional guidelines, the German law for animal protection, the Directive 2010/63/EU and FELASA (Federation of European Laboratory Animal Science Associations, Ipswich, UK) guidelines.

Informed Consent Statement: Not applicable.

Data Availability Statement: Not applicable.

Conflicts of Interest: The authors declare no conflict of interest. Brandenburg Antiinfektiva had no role in the design of the study; in the collection, analyses, or interpretation of data; in the writing of the manuscript, or in the decision to publish the results. 


\section{References}

1. Nikaido, H. Multidrug resistance in bacteria. Annu. Rev. Biochem. 2009, 78, 119-146. [CrossRef]

2. Kock, R.; Becker, K.; Cookson, B.; van Gemert-Pijnen, J.E.; Harbarth, S.; Kluytmans, J.; Mielke, M.; Peters, G.; Skov, R.L.; Struelens, M.J.; et al. Methicillin-Resistant Staphylococcus Aureus (MRSA): Burden of Disease and Control Challenges in Europe. Euro Surveill. Bull. Eur. Sur Les Mal. Transm. Eur. Commun. Dis. Bull. 2010, 15, 19688. [CrossRef] [PubMed]

3. Buddeberg, B.S.; Aveling, W. Puerperal sepsis in the 21st century: Progress, new challenges and the situation worldwide. Postgrad. Med. J. 2015, 91, 572-578. [CrossRef] [PubMed]

4. Projan, S.J. Why is big Pharma getting out of antibacterial drug discovery? Curr. Opin. Microbiol. 2003, 6, 427-430. [CrossRef]

5. Projan, S.J.; Shlaes, D.M. Antibacterial drug discovery: Is it all downhill from here? Clin. Microbiol. Infect. Off. Publ. Eur. Soc. Clin. Microbiol. Infect. Dis. 2004, 10, 18-22. [CrossRef] [PubMed]

6. Loughran, D.; Harrison, J. Antibiotic resistance: A long term, serious problem ... getting worse. Thoughts on the future of surgery in a post-antibiotic era. Eur. Surg. 2014, 46, 55-56. [CrossRef]

7. Nakatsuji, T.; Gallo, R.L. Antimicrobial Peptides: Old Molecules with New Ideas. J. Investig. Dermatol. 2012, 132, 887-895. [CrossRef]

8. Van Amersfoort, E.S.; Van Berkel, T.J.; Kuiper, J. Receptors, mediators, and mechanisms involved in bacterial sepsis and septic shock. Clin. Microbiol. Rev. 2003, 16, 379-414. [CrossRef] [PubMed]

9. Angus, D.C.; van der Poll, T. Severe Sepsis and Septic Shock. N. Engl. J. Med. 2013, 369, 840-851. [CrossRef]

10. Gutsmann, T.; Razquin-Olazarán, I.; Kowalski, I.; Kaconis, Y.; Howe, J.; Bartels, R.; Hornef, M.; Schürholz, T.; Rössle, M.; Sanchez-Gómez, S.; et al. New Antiseptic Peptides To Protect against Endotoxin-Mediated Shock. Antimicrob. Agents Chemother. 2010, 54, 3817-3824. [CrossRef]

11. Schuerholz, T.; Doemming, S.; Hornef, M.; Martin, L.; Simon, T.-P.; Heinbockel, L.; Brandenburg, K.; Marx, G. The antiinflammatory effect of the synthetic antimicrobial peptide 19-2.5 in a murine sepsis model: A prospective randomized study. Crit. Care 2013, 17, R3. [CrossRef]

12. de Tejada, G.M.; Heinbockel, L.; Ferrer-Espada, R.; Heine, H.; Alexander, C.; Bárcena-Varela, S.; Goldmann, T.; Correa, W.; Wiesmüller, K.-H.; Gisch, N.; et al. Lipoproteins/peptides are sepsis-inducing toxins from bacteria that can be neutralized by synthetic anti-endotoxin peptides. Sci. Rep. 2015, 5, 14292. [CrossRef] [PubMed]

13. Correa, W.; Heinbockel, L.; Behrends, J.; Kaconis, Y.; Barcena-Varela, S.; Gutsmann, T.; Mauss, K.; Schürholz, T.; Schromm, A.B.; de Tejada, G.M.; et al. Antibacterial action of synthetic antilipopolysaccharide peptides (SALP) involves neutralization of both membrane-bound and free toxins. FEBS J. 2019, 286, 1576-1593. [CrossRef] [PubMed]

14. Heinbockel, L.; Sánchez-Gómez, S.; de Tejada, G.M.; Dömming, S.; Brandenburg, J.; Kaconis, Y.; Hornef, M.; Dupont, A.; Marwitz, S.; Goldmann, T.; et al. Preclinical Investigations Reveal the Broad-Spectrum Neutralizing Activity of Peptide Pep19-2.5 on Bacterial Pathogenicity Factors. Antimicrob. Agents Chemother. 2013, 57, 1480-1487. [CrossRef] [PubMed]

15. Alshammari, T.M.; Al-Hassan, A.A.; Hadda, T.B.; Aljofan, M. Comparison of different serum sample extraction methods and their suitability for mass spectrometry analysis. Saudi Pharm. J. 2015, 23, 689-697. [CrossRef]

16. Moreno-Bondi, M.C.; Marazuela, M.D.; Herranz, S.; Rodriguez, E. An overview of sample preparation procedures for LC-MS multiclass antibiotic determination in environmental and food samples. Anal. Bioanal. Chem. 2009, 395, 921-946. [CrossRef]

17. Wang, H.Y.; Jackson, S.N.; Woods, A.S. Direct MALDI-MS analysis of cardiolipin from rat organs sections. J. Am. Soc. Mass Spectrom. 2007, 18, 567-577. [CrossRef]

18. Uhl, P.; Fricker, G.; Haberkorn, U.; Mier, W. Radionuclides in drug development. Drug Discov. Today 2015, 20, 198-208. [CrossRef]

19. Paquet, A. Introduction of 9-fluorenylmethyloxycarbonyl, trichloroethoxycarbonyl, and benzyloxycarbonyl amine protecting groups into O-unprotected hydroxyamino acids using succinimidyl carbonates. Can. J. Chem. 1982, 60, 976-980. [CrossRef]

20. Schieck, A.; Muller, T.; Schulze, A.; Haberkorn, U.; Urban, S.; Mier, W. Solid-Phase synthesis of the lipopeptide Myr-HBVpreS/2-78, a hepatitis B virus entry inhibitor. Molecules 2010, 15, 4773-4783. [CrossRef]

21. Aleman, C.L.; Noa, M.; Mas, R.; Rodeiro, I.; Mesa, R.; Menendez, R.; Gamez, R.; Hernandez, C. Reference data for the principal physiological indicators in three species of laboratory animals. Lab. Anim. 2000, 34, 379-385. [CrossRef] [PubMed] 